\title{
Development and reliability testing of the Comprehensive High-Level Activity Mobility Predictor (CHAMP) in male servicemembers with traumatic lower-limb loss
}

\author{
Robert S. Gailey, PhD, PT; ${ }^{1-2^{*}}$ Ignacio A. Gaunaurd, PhD, MSPT; ${ }^{1}$ Michele A. Raya, PhD, PT, SCS, ATC; ${ }^{2}$ \\ Kathryn E. Roach, PhD, PT; ${ }^{2}$ Alison A. Linberg, DPT, ATC; ${ }^{3}$ MAJ (Ret) Stuart M. Campbell, MPT; ${ }^{4}$ LTC \\ Daniel M. Jayne, MPT, OCS ${ }^{5}$ COL (Ret) Charles Scoville, PT, DPT ${ }^{3}$ \\ ${ }^{1}$ Functional Outcomes Research and Evaluation Center, Miami Department of Veterans Affairs Healthcare System, \\ Miami, FL; ${ }^{2}$ Department of Physical Therapy, Miller School of Medicine, University of Miami, Coral Gables, FL; \\ ${ }^{3}$ Military Advanced Training Center, Walter Reed Army Medical Center, Washington, DC; ${ }^{4}$ Center for the Intrepid, \\ Brooke Army Medical Center, San Antonio, TX; ${ }^{5}$ Womack Army Medical Center, Fort Bragg, Fayetteville, NC
}

\begin{abstract}
The opportunity for wounded servicemembers (SMs) to return to high-level activity and return to duty has improved with advances in surgery, rehabilitation, and prosthetic technology. As a result, there is now a need for a high-level mobility outcome measure to assess progress toward high-level mobility during and after rehabilitation. The purpose of this study was to develop and determine the reliability of a new outcome measure called the Comprehensive High-Level Activity Mobility Predictor (CHAMP). The CHAMP consists of the Single Limb Stance, Edgren Side Step Test, T-Test, and Illinois Agility Test. CHAMP reliability was determined for SMs with lower-limb loss (LLL) (interrater: $n=118$; test-retest: $n=111)$ and without LLL ( $n=$ 97). A linear system was developed to combine the CHAMP items and produce a composite score that ranges from 0 to 40 , with higher scores indicating better performance. Interrater and test-retest intraclass correlation coefficient values for the CHAMP were 1.0 and 0.97 , respectively. A CHAMP score equal to or greater than 33 points is within the range for SMs without LLL. The CHAMP was found to be a safe and reliable measure of high-level mobility in SMs with traumatic LLL.
\end{abstract}

Key words: agility, high-level activity, lower-limb loss, military personnel, mobility, OIF/OEF, outcome measures, reliability, traumatic amputation, Veterans.

\begin{abstract}
Abbreviations: $\mathrm{AD}=$ Active Duty, $\mathrm{BAMC}=$ Brooke Army Medical Center, BTFA = bilateral transfemoral amputation, BTTA $=$ bilateral transtibial amputation, CHAMP = Comprehensive High-Level Activity Mobility Predictor, CI = confidence interval, ESST $=$ Edgren Side Step Test, HUC = Human Use Committee, IAT = Illinois Agility Test, ICC $=$ intraclass correlation coefficient, IRB $=$ Institutional Review Board, LLL = lower-limb loss, MBP $=$ Medicine Ball Put, $\mathrm{MDC}=$ minimal detectable change, NMCSD = Naval Medical Center San Diego, $\mathrm{OEF}=$ Operation Enduring Freedom, OIF = Operation Iraqi Freedom, SD = standard deviation, SEM = standard error of measurement, SLS = Single Limb Stance, SM = servicemember, $\mathrm{TFA}=$ unilateral transfemoral amputation, TTA $=$ unilateral transtibial amputation, TTA/TFA = transtibial and transfemoral amputations, VA = Department of Veterans Affairs, Womack = Womack Army Medical Center, WRAMC $=$ Walter Reed Army Medical Center, WRNMMC $=$ Walter Reed National Military Medical Center.

*Address all correspondence to Robert S. Gailey, PhD, PT; Department of Physical Therapy, Miller School of Medicine, University of Miami, 5915 Ponce de Leon Blvd, Plummer Bldg, 5th floor, Coral Gables, FL 33146; 305-284-4535; fax: 305-378-4107. Email: rgailey@miami.edu http://dx.doi.org/10.1682/JRRD.2012.05.0099
\end{abstract}




\section{INTRODUCTION}

Over the past decade, opportunities for today's young, fit, athletic servicemembers (SMs) with traumatic lowerlimb loss (LLL) have changed dramatically. In prior conflicts, it was anticipated that the majority of SMs would retire from the Armed Forces after experiencing LLL. Today, it is not uncommon for SMs with traumatic LLL to return to Active Duty (AD) [1-2]. Several factors are associated with providing SMs with LLL from recent conflicts the ability to return to $\mathrm{AD}$ : elite fitness level of the SM prior to injury and the state-of-the-art rehabilitation received after injury at medical treatment facilities at Walter Reed Army Medical Center (WRAMC), Washington, DC; Brooke Army Medical Center (BAMC), San Antonio, Texas; National Naval Medical Center, Bethesda, Maryland; or Naval Medical Center San Diego (NMCSD), San Diego, California. In addition, returning SMs have access to the most recent prosthetic technology and regular exposure to a variety of sports and recreational activities in an effort to facilitate a premorbid level of activity and the option of returning to $\mathrm{AD}[3-4]$.

Prior to LLL, these SMs were performing at an elite level of physical fitness and considered tactical athletes. The rehabilitative goal for any motivated injured athlete or wounded SM is to achieve his or her own optimal level of function. Clinicians therefore need a method to quantify the SM's current level of mobility, to document the changes in mobility over time, and to assess when the SM has reached his or her prior or maximum potential level of functional mobility. The clinical value of functional outcome measures is to allow the clinician to achieve these objectives. Pasquina and Fitzpatrick observed that SMs with LLL receiving rehabilitation postinjury at WRAMC were achieving maximum scores on the standard outcome measures shortly after being fit with their initial prosthesis [5]. They concluded that the available outcome measures of mobility following LLL were subject to a ceiling effect and could not measure the effect of the high-level rehabilitation provided to this new generation of SMs with traumatic LLL. Therefore, they recommended developing a single measure that could quantify mobility capabilities consistent with the requirements of tactical athletes or SMs. It should include the multiple components required for high-level mobility. This measure should also detect changes in high-level mobility throughout the rehabilitation process and assist with the decisions concerning return to high-level activity.
The sports literature is replete with outcome measures that assess the different physical performance factors required for high-level mobility: balance, postural stability, coordination, power, speed, and agility [6-16]. These physical performance factors are essential to the SM's role as a tactical athlete when performing highlevel activities such as running, sports, and preparing for military maneuvers [17]. Because descriptive reports of performance can be subjective, open to interpretation, and cannot be quantified, the use of assessment tools that produce numerical values tend to have greater clinical merit. A single numeric value can be quickly read, retest scores can indicate improvement or decline in performance, and familiarity of the numeric scale allows clinicians to gauge performance and identify benchmarks. Performance-based measures often combine a number of individual tests to create a single instrument that produces one score that will provide the clinician with an allinclusive assessment of the intended construct [18-20]. This type of testing with multiple domains affords the tester insights to a diverse number of contributing factors that can either assist in determining the contribution to overall function or isolate a single limitation, e.g., the measure of general mobility versus a limitation of movement in one specific direction with or without a degree of speed, power, or balance. Because high-level mobility consists of multiple physical performance factors, one activity or movement in one plane may not provide a comprehensive or global assessment of mobility relevant to an SM as a tactical athlete. In SMs with LLL, the construct of high-level mobility has multiple facets, some of which are unique to this population. Although existing measures address individual aspects of the construct, none of them incorporated all of the performance factors. Therefore, it was necessary to develop a test of high-level mobility that includes a combination of balance-, power-, and agility-type activities performed in multiple planes of motion. Since the aim of this instrument was to document high-level mobility performance as a multifaceted construct, it was important that the instrument generate a single numeric value that could be used to document improvement or decline in high-level mobility.

The purpose of this study was to (1) develop a safe performance-based measure of high-level mobility for those with LLL for use once a minimal level of prosthetic competency was achieved, (2) determine the interrater and test-retest reliability of the instrument's individual items and composite score, (3) establish the standard error of measurement (SEM) and minimal detectable 
change (MDC) for the composite score, and (4) determine the internal consistency of the instrument's individual test items. The instrument designed to meet criteria for this target population was named the Comprehensive High-Level Activity Mobility Predictor (CHAMP).

\section{METHODS}

\section{CHAMP Development and Item Selection}

The primary intention of the CHAMP was to assess the physical performance factors of high-level mobility, as identified by the U.S. Army Center for Health Promotion and Preventive Medicine [17]. In addition, highlevel mobility needed to be defined. For the purpose of this study, we define high-level mobility as advanced rank function involving change in body position or location by moving from one place to another by rapidly walking and/or running.

It was considered essential that the CHAMP could be performed safely by all SMs with LLL who demonstrated a predetermined level of prosthetic function. The predetermined level of function ensures that the SM with LLL is demonstrating proficient strength, balance, postural stability, prosthetic control, and endurance to perform speed, power, and agility activities regardless of level of amputation or number of limbs lost. In addition, it should be possible to perform the test in a typical clinical setting, using minimal equipment, and within a reasonable time frame. The test also had to be reliable, with good internal consistency and free from ceiling effects.

Because high-impact activities such as jumping or hopping could produce harmful friction or shear forces at the stump/socket interface, potentially causing damage to healing or recently healed tissues, traditional sports performance measures that require jumping (Vertical Jump Test [6-8], 5 Jump Horizontal Test [10]), hopping (Hexagon Test [9,21], Single Hop [16,22], Triple Hop [23], or 5 Hop Test [24]), and running for long distances (Army Physical Fitness Test 2 Mile Run [8]) were not considered for the CHAMP.

Coordination, power, speed, and agility are important physical components necessary for successful performance in sports, recreational activities, and combat readiness $[9,17]$. In order to assess coordination, power, speed, and agility in SMs with LLL, it was essential that the tests determine how quickly an individual could move a certain distance, start and stop, change directions, and efficiently change body position [17]. It was also determined that a comprehensive instrument of high-level activity should include a combination of agility-type activities progressing from a single plane of motion to biplanar and finally multiple planes to ensure that each requisite movement can be completed and performed safely before performing the next.

The criteria for designing the CHAMP were to (1) identify the minimal number of test items that would assess coordination, power, speed, and agility in multiple planes, without hopping or jumping, yielding a single composite score and (2) ensure that all tests could be performed safely in a clinical setting after a moderate level of mobility was achieved. The following five existing performancebased outcome measures were considered for inclusion in the CHAMP: Single Limb Stance (SLS), Medicine Ball Put (MBP), Edgren Side Step Test (ESST), T-Test, and Illinois Agility Test (IAT). The tests were performed in the sequence listed. The SLS was included to assess balance and postural stability with the ability to predict prosthetic ambulation potential in SMs with LLL [25-28]. The ability for an SM with LLL to balance on the nondisabled limb was used to determine whether he or she was ready to perform the more demanding CHAMP items. The ESST was included as a test of unidirectional frontal plane agility and body control [6-7]. The T-Test assesses bidirectional (sagittal and frontal) agility and body control, evaluating the ability to change directions rapidly while maintaining balance, speed, and power in the forward, lateral, and backward directions [6,9-10]. The IAT was included as a measure of multidirectional (frontal, sagittal, and transverse) agility, emphasizing the ability to accelerate and decelerate when performing a variety of maneuvers [1114,29-31].

The MBP is a standard measure of upper-body power [8]. It was assumed that SMs with LLL and without upper-limb amputation at peak fitness prior to LLL would demonstrate upper-body power equivalent to their peers without LLL. The MBP test was included to determine physical power differences between groups.

\section{Study Design}

This two-phase, cross-sectional, multisite study was conducted at WRAMC; Center for the Intrepid, BAMC; and Womack Army Medical Center (Womack), Fort Bragg, North Carolina. Phase I established normative CHAMP performance data with a convenience sample of 97 AD U.S. Army Soldiers without LLL stationed at Fort 
Bragg, North Carolina. AD individuals were included in the study if they were male and between 18 and $40 \mathrm{yr}$ old. Participants were excluded if they had a physical profile at the time of enrollment (physical profile is defined as any condition associated with an illness, injury, or surgery that requires the SM to be restricted from returning to full functional duty).

Phase II was performed at all three test sites where SMs with traumatic LLL were recruited: 118 participants with LLL completed interrater reliability testing and 111 returned to complete the test-retest reliability testing (Figure). Participants were either AD or retired male SMs between the ages of 18 and 40 with LLL who were medically stable with a properly fitting prosthesis and demonstrated a minimal level of function, defined as an Amputee Mobility Predictor score of at least 37 points and/or 6-Minute Walk Test distance of at least $250 \mathrm{~m}$. Female SMs were not examined in phases I or II because they compromise a very small percentage $(3 \%)$ of SMs who have experienced traumatic LLL in recent Operation Iraqi Freedom (OIF) and Operation Enduring Freedom
(OEF) conflicts $[2,32]$. Participants were excluded if they had spinal cord injury; upper-limb loss; peripheral nerve injury limiting function; inability to follow commands due to traumatic brain injury; or orthopedic, cardiopulmonary, or contralateral limb injuries limiting mobility or exercise tolerance. Levels of amputation were classified as unilateral transtibial amputation (TTA), unilateral transfemoral amputation (TFA), bilateral transtibial amputation (BTTA), bilateral transfemoral amputation (BTFA), or combination of transtibial and transfemoral amputations (TTA/TFA). The SMs with LLL demonstrated a range of recovery from just completing skilled rehabilitation to fully rehabilitated and returning to $\mathrm{AD}$.

\section{Study Procedures}

Prior to signing Institutional Review Board (IRB)approved informed consent and protected health information documents, an investigator reviewed and explained eligibility criteria, methodology, confidentiality, and potential risks involved with each participant.

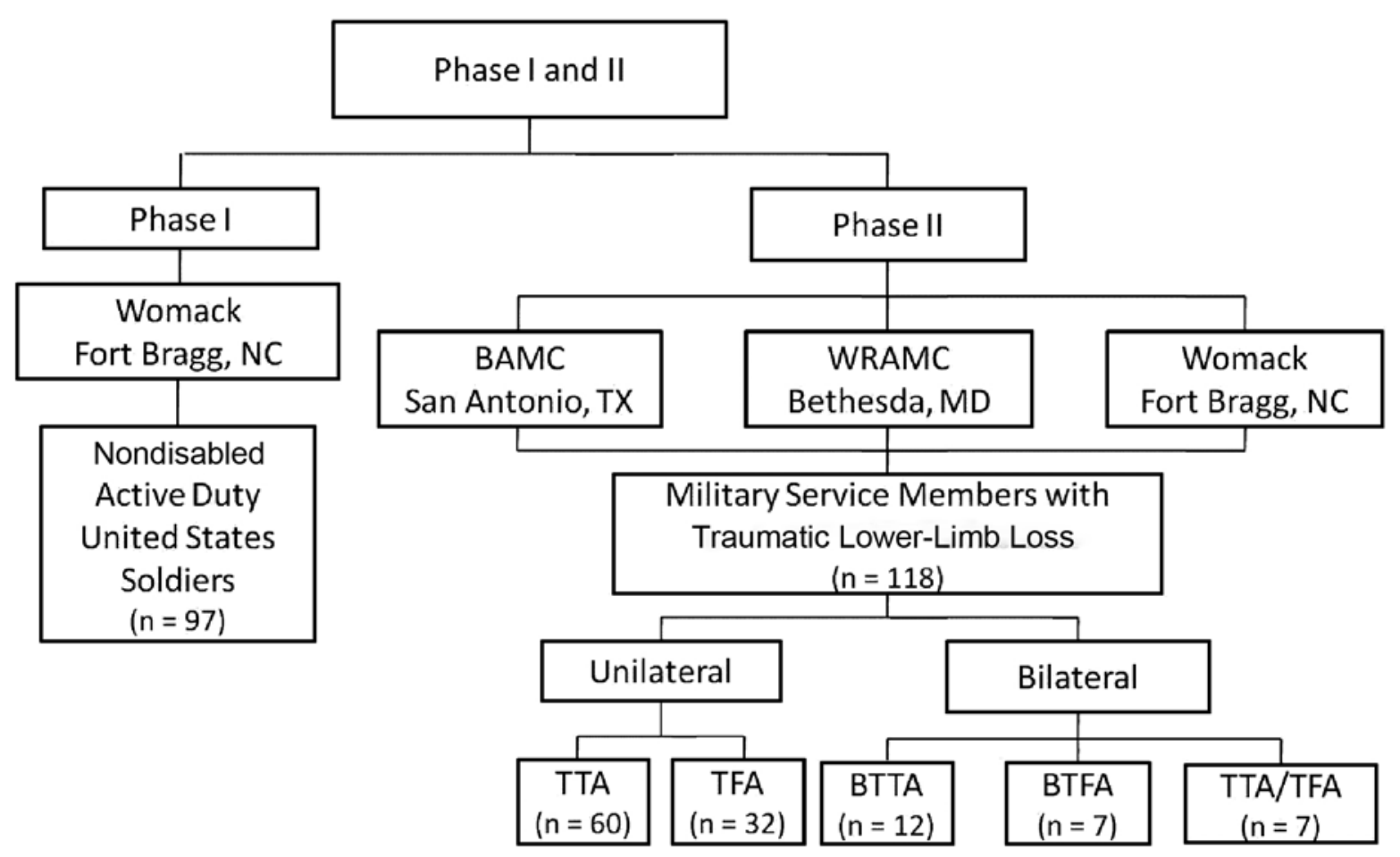

Figure.

Comprehensive High-Level Activity Mobility Predictor study design. BAMC $=$ Brooke Army Medical Center, BTFA $=$ bilateral transfemoral amputation, BTTA = bilateral transtibial amputation, TFA = unilateral transfemoral amputation, TTA = unilateral transtibial amputation, TTA/TFA = transtibial and transfemoral amputations, Womack $=$ Womack Army Medical Center, WRAMC $=$ Walter Reed Army Medical Center. 
Two physical therapists employed by participating Armed Forces Amputee Patient Care Program Rehabilitation Centers interviewed all participants for this study to collect information on demographic characteristics and current medical conditions, symptoms, and pain. In addition, they measured anthropometric characteristics such as height, weight, and waist circumference. Table 1 provides a description of baseline characteristics for study participants.

Participants were asked to dress in military-style physical training uniforms, which include shorts, T-shirt, socks, and sneakers. The SMs with LLL wore the same prosthesis on both testing sessions. The participants were randomly assigned to two trained raters who simultaneously observed and independently recorded all testing results. Prior to data collection, all raters attended formal training sessions on administering and scoring the CHAMP. Twelve teams of two raters were used for data collection. Rater 1 read the scripted instructions for each CHAMP test item while rater 2 walked the test course to ensure that each subject understood the course pattern. Raters did not verbally motivate or offer performance enhancement suggestions. Both raters timed or scored the participant's performance separately and were not allowed to view each other's recording sheet. Participants performed two to three trials of each test, with the best score used for data analysis. The participants performed the CHAMP test in the following order: SLS, MBP, ESST, T-Test, and IAT. A description of each CHAMP item and instructional guidelines for their administration is found in the Appendix (available online only).

Table 1.

Characteristics of U.S. servicemembers with and without traumatic lower-limb loss (LLL).

\begin{tabular}{|c|c|c|c|c|c|}
\hline Characteristic & \multicolumn{2}{|c|}{ Servicemembers with LLL } & \multicolumn{2}{|c|}{ Servicemembers without LLL } & $p$-Value \\
\hline Height (cm) & $118(100)$ & $181.6 \pm 7.1(158.8-203.2)$ & $97(100)$ & $177.92 \pm 6.47(163.8-193.1)$ & $<0.001$ \\
\hline Waist Circumference (cm) & $118(100)$ & $94.16 \pm 9.96(71.1-125.1)$ & $97(100)$ & $86.08 \pm 6.96(69.2-104.1)$ & $<0.001$ \\
\hline Time Since Traumatic Injury (yr) & $118(100)$ & $3.2 \pm 1.9(0.3-12.0)$ & - & - & - \\
\hline \multicolumn{6}{|l|}{ Amputation Level } \\
\hline BTTA & $12(11)$ & - & - & - & - \\
\hline BTFA & $7(6)$ & - & - & - & - \\
\hline TTA/TFA & $7(6)$ & - & - & - & - \\
\hline \multicolumn{6}{|l|}{ Marital Status } \\
\hline Single & $40(34)$ & - & $45(46)$ & - & - \\
\hline 1-3 Years of College & $56(47)$ & - & $39(41)$ & - & - \\
\hline College Graduate with 4-Year Degree & $9(8)$ & - & $13(13)$ & - & - \\
\hline Some Graduate School & $5(4)$ & - & $6(6)$ & - & - \\
\hline \multicolumn{6}{|l|}{ Race/Ethnicity } \\
\hline White/Caucasian & $94(80)$ & - & $78(81)$ & - & - \\
\hline Black/African American & $19(16)$ & - & $12(12)$ & - & - \\
\hline Asian & $1(1)$ & - & $4(4)$ & - & - \\
\hline Native Hawaiian or Pacific Islander & $4(3)$ & - & $3(3)$ & - & - \\
\hline \multicolumn{6}{|l|}{ Military Status } \\
\hline Awaiting Disposition & $42(36)$ & - & - & - & - \\
\hline Active Duty (nondeployed) & $32(27)$ & - & - & - & - \\
\hline
\end{tabular}


For the MBP test, the participant held the $6 \mathrm{lb}$ ball with both hands with the ball touching his chest. When ready, the participant put the medicine ball as far as possible. The distance was measured from the front legs of the chair with the best put of two trials recorded; $30 \mathrm{~s}$ rest periods were given between each put.

Participants who agreed to take part in the test-retest reliability phase of the study were scheduled to return between 24 to $72 \mathrm{~h}$ after initial testing. The participants were asked to avoid unaccustomed physical activities between test dates.

\section{Statistical Analysis}

Data was entered into Excel worksheets (Microsoft; Redmond, Washington), and analysis was performed with SAS version 9.13 (SAS Institute Inc; Cary, North Carolina). Descriptive statistics were used to characterize the study sample. The mean time to complete the CHAMP was calculated by combining the time required to complete each item and the standard rest periods between tests. The number of adverse events that occurred during testing was tabulated.

For the SMs with and without LLL, the best performance among the two to three trials completed for each of the CHAMP items for rater 1 was used for analysis. Student $t$-test was used to compare raw CHAMP item scores of SMs with and without LLL. CHAMP items were considered for inclusion in the CHAMP if significant differences $(p<0.05)$ were found between SMs with and without LLL.

\section{CHAMP Development}

Differences between SMs with and without LLL were found in all four of the CHAMP items: SLS, ESST, T-Test, and IAT. Differences in upper-body power, as assessed by the MBP, were not found between SMs with and without LLL, which indicated that both groups were similar in upper-body power, and by extension, as a group would have had similar power in the lower limbs if not injured (Table 2). Therefore, both groups were equally matched and can be compared in terms of differences based on loss of limb and concomitant injury.

The four CHAMP items each use a different scoring system. The SLS recorded the time a subject could balance on one limb, with a maximum score of $30 \mathrm{~s}$ on each leg. High SLS scores indicated better performance, but a ceiling effect exists. All SMs without LLL achieved maximum times of $30 \mathrm{~s}$ for both legs. Many, but not all, participants with unilateral LLL stood for $30 \mathrm{~s}$ on their contralateral limb. However, SMs with bilateral LLL stood well below $30 \mathrm{~s}$ on both lower limbs. Therefore, it was decided to add the right- and left-sided SLS into one combined time.

Two of the tests, the IAT and T-Test, were timed. The scores for these tests were measured in seconds, with lower times indicating better performance. The ESST was time limited and scored based on the number of $1 \mathrm{~m}$ spans crossed within the allotted $10 \mathrm{~s}$ time period, with greater distance indicating better performance. To combine the CHAMP items, all of the tests were converted to the same scoring system. The distribution of the scores was examined on all tests for SMs with and without LLL, and significant overlap was found between the performances of both groups. In fact, the highest score on the ESST was achieved by an SM with TTA. Based on the distribution of scores, it was clear that any attempt to use percentiles to develop a scoring system would diminish and distort the responsiveness of the underlying tests. For example, a $1 \mathrm{~s}$ decrease in time to perform the T-Test from 14.1 to $13.1 \mathrm{~s}$ would produce a change in percentile of 17.8 to 9.3 percent, while a $1 \mathrm{~s}$ decrease in time to perform the T-Test from 34.6 to $33.6 \mathrm{~s}$ would produce a change in percentile of 82.2 to 81.4 percent. The result

Table 2.

Descriptive statistics for total Comprehensive High-Level Activity Mobility Predictor (CHAMP) score and CHAMP test items for Active Duty U.S. Army servicemembers without lower-limb loss (LLL) $(n=97)$ and with traumatic LLL $(n=118)$.

\begin{tabular}{lcc}
\hline \multicolumn{1}{c}{ CHAMP Test Item } & $\begin{array}{c}\text { Servicemembers without LLL, } \\
\text { Mean } \pm \text { SD (Range) }\end{array}$ & $\begin{array}{c}\text { Servicemembers with LLL, } \\
\text { Mean } \pm \text { SD (Range) }\end{array}$ \\
\hline Single Limb Stance (s) & - & $25.0 \pm 14.6(0-60)$ \\
Medicine Ball Put (m) & $6.3 \pm 0.8(4.7-8.4)$ & $6.4 \pm 0.9(4.5-8.6)$ \\
Edgren Side Step Test (m) & $24.3 \pm 2.3(20-30)$ & $15.4 \pm 5.5(3-32)$ \\
T-Test (s) & $12.2 \pm 1.0(10.1-15.0)$ & $25.5 \pm 17.8(10.9-123.7)$ \\
Illinois Agility Test (s) ${ }^{*}$ & $18.2 \pm 1.2(15.1-23.4)$ & $32.1 \pm 12.8(17.6-87.3)$ \\
Total CHAMP Score & $35.4 \pm 1.2(33-39)$ & $21.8 \pm 7.8(1-35)$ \\
${ }^{*}$ Significant differences between servicemembers with and without LLL $(p<0.001)$. & \\
SD = standard deviation. & \\
\hline \hline
\end{tabular}


would be a test much less sensitive to change in individuals at the lower end of the range, the very individuals who would be most likely to participate in rehabilitation.

To produce a scoring system that would be responsive to change in high-level mobility performance, a 0 to 10 scoring system was developed for each item. For the ESST, T-Test, and IAT, the 0 designated scores lower than the range recorded in this study. This was done to distinguish SMs who performed at lower levels than the test group of participants. The 0 score for the SLS indicates that an SM could not balance for even $1 \mathrm{~s}$ on either leg. Cut points for assigning scores of 10 were based on the high scores of SMs with and without LLL. The CHAMP items were assigned points from 1 to 9 using equal score intervals. The exception to this system was the SLS, which used whole numbers and fractions such as 0.5 to 9 . This scoring system produced scores ranging from 0 to 10 for each of the CHAMP items.

To generate a CHAMP score, the best times or points for each individual CHAMP item was converted to a 0 to 10 scoring system, using the CHAMP Scoring System in the Appendix (available online only). The scores for each individual item are added to produce a composite CHAMP score with a 0 to 40 scoring range, with 40 representing the highest level of performance.

The intraclass correlation coefficient (ICC) was calculated to determine the interrater and test-retest reliability of the CHAMP item raw scores and total CHAMP score using model 2,1 . We reported the 95 percent confidence interval (CI) for all ICC values. For interrater reliability, comparison of agreement was analyzed between raters 1 and 2 for session 1. For test-retest reliability, comparison of agreement was analyzed between sessions 1 and 2 for rater 1 of each rater team.

The SEM of the total CHAMP score was calculated using the test-retest reliability coefficient $(r)$ and standard deviation (SD) of the CHAMP for the participants with LLL (Equation (1)):

$$
\mathrm{SEM}=\mathrm{SD}_{1-r}
$$

The MDC for the total CHAMP score was calculated using the distribution-based method and the following formula (Equation (2)):

$$
\begin{gathered}
\mathrm{MDC}=\mathrm{z} \text {-score } \\
\sqrt{\text { level of confidence }} \times \mathrm{SD}_{\text {baseline }} \times \\
\sqrt{ }\left(2\left[1-r_{\text {test-retest }}\right]\right) .
\end{gathered}
$$

The z-score represents the CI from the normal distribution. We used 95 percent CI for the study population, making the $z$-score $=1.96$. The SD used for analysis was from the total CHAMP score results for the SMs with LLL (SD = 7.81). The ICC for the total CHAMP score's test-retest reliability in SMs with LLL was used for $r(r=0.97)$. A multiplier of the $\sqrt{ } 2$ was used to account for the increased error in calculating the test-retest reliability with two different data sets at two different points in time [33-34].

The internal consistency or homogeneity of the CHAMP items was examined to determine whether the items measured the different physical performance factors of high-level mobility using the following: (1) Spearman correlation coefficient determined the correlation between the CHAMP items and CHAMP score, (2) Cronbach $\alpha$ determined the internal consistency of the CHAMP, and (3) itemto-total correlation examined between the CHAMP items.

\section{RESULTS}

Table 1 describes the baseline characteristics of the SMs with and without LLL. Of the 118 SMs with LLL, 60 had TTA, 32 had TFA, 12 had BTTA, 7 had BTFA, and 7 had TTA/TFA. Of the total 111 SMs with LLL who completed the test-retest reliability study, 55 had TTA, 31 had TFA, 11 had BTTA, 7 had BTFA, and 7 had TTA/ TFA. The mean \pm SD age, height, and weight of the 111 SMs with LLL who completed the test-retest reliability study was $28.9 \pm 5.6 \mathrm{yr}, 181.4 \pm 7.2 \mathrm{~cm}$, and $90.18 \pm$ $15.03 \mathrm{~kg}$, respectively. No differences $(p<0.05)$ in baseline characteristics were found between the interrater and test-retest reliability sample population of SMs with LLL.

Differences were found in the baseline characteristics of age, height, weight, and waist circumference between the SMs with and without LLL $(p<0.001)$. Difference in age was found between those with TFA (mean age: $30.6 \mathrm{yr}, p=$ 0.01 ) and SMs without LLL. Difference in height was found between those with TTA (mean height: $181.4 \mathrm{~cm}, p=0.04$ ) and SMs without LLL. Differences in weight were seen between those with BTTA (mean weight: $97.7 \mathrm{~kg}, p=0.01$ ), TFA (mean weight: $91.1 \mathrm{~kg}, p=0.01$ ), TTA (mean weight: $89.7 \mathrm{~kg}, p=0.01$ ), and SMs without LLL. Differences in waist circumference were seen between those SMs with and without LLL $(p<0.001)$, except for those with BTFA (mean waist circumference: $87.3 \mathrm{~cm}, p=0.99$ ). Significant differences between marital status, education, and race/ ethnicity were not seen between the SMs with and without LLL $(p>0.05)$. 
The average time to complete the CHAMP was $14.03 \pm$ $0.78 \mathrm{~min}$, with a range between 12.60 and $18.70 \mathrm{~min}$ for SMs with LLL. The safety of the CHAMP was demonstrated by the finding that, of the 215 total participants who performed 3,842 trials throughout this study, only one adverse event occurred as the result of a prosthetic issue. After examination, the participant voluntarily completed the CHAMP testing without difficulty.

Tables 3 and 4 describe the score distribution for total CHAMP scores and converted and unconverted CHAMP item scores for SMs with and without LLL. A smaller variance was observed among the distribution of total CHAMP scores and individual CHAMP items scores for the SMs without LLL. The range in scores for the participants without LLL fell within the upper range of performance for total CHAMP score and individual CHAMP items. A large variance, which spanned the entire scoring range for both the total CHAMP score and individual CHAMP items, was observed among the SMs with LLL.
Table 2 compares CHAMP item performance and total CHAMP score for the SMs with and without LLL. The SLS was not analyzed for the participants without LLL because they were all able to stand for $30 \mathrm{~s}$ on each limb. Student $t$-test results demonstrated significant differences between test performance of the SMs with and without LLL for the ESST, T-Test, IAT, and total CHAMP score. As stated previously, because there was no difference in MBP performance between the SMs with and without LLL, MBP was not included in the CHAMP.

Table 5 reports the ICC for interrater and test-retest reliability for the CHAMP items and total CHAMP score. The ICCs for interrater reliability for the CHAMP items ranged from 0.97 (95\% CI: 0.95-0.98) for the ESST to 1.0 for SLS, T-Test, and IAT. The ICCs for testretest reliability of the CHAMP items ranged from 0.97 (95\% CI: $0.87-0.93$ ) for the ESST to 0.99 for the SLS. The ICCs for interrater and test-retest reliability for the total CHAMP score were 1.0 and 0.97 (95\% CI: $0.95-$ $0.98)$, respectively.

Table 3.

Score distribution for total Comprehensive High-Level Activity Mobility Predictor (CHAMP) score and CHAMP test items for Active Duty U.S. servicemembers without lower-limb loss $(n=97)$.

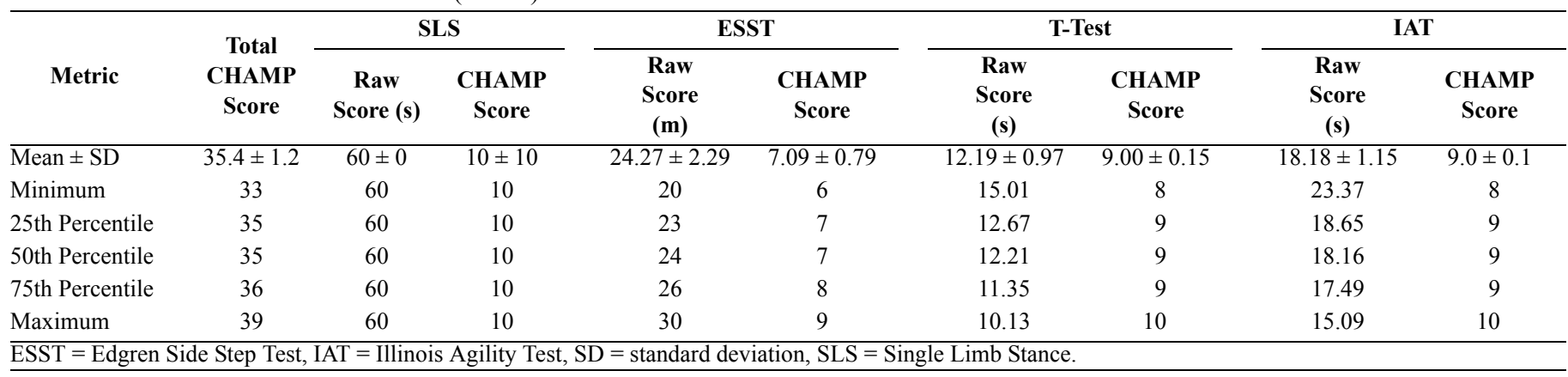

Table 4.

Score distribution for total Comprehensive High-Level Activity Mobility Predictor (CHAMP) score and CHAMP test items for U.S. servicemembers with lower-limb loss $(n=118)$.

\begin{tabular}{|c|c|c|c|c|c|c|c|c|c|}
\hline \multirow[b]{2}{*}{ Metric } & \multirow{2}{*}{$\begin{array}{c}\text { Total } \\
\text { CHAMP } \\
\text { Score }\end{array}$} & \multicolumn{2}{|c|}{ SLS } & \multicolumn{2}{|c|}{ ESST } & \multicolumn{2}{|c|}{ T-Test } & \multicolumn{2}{|c|}{ IAT } \\
\hline & & $\begin{array}{c}\text { Raw } \\
\text { Score (s) }\end{array}$ & $\begin{array}{c}\text { CHАMP } \\
\text { Score }\end{array}$ & $\begin{array}{c}\text { Raw } \\
\text { Score } \\
(\mathbf{m})\end{array}$ & $\begin{array}{c}\text { CHАMP } \\
\text { Score }\end{array}$ & $\begin{array}{c}\text { Raw } \\
\text { Score } \\
\text { (s) }\end{array}$ & $\begin{array}{c}\text { СНАМР } \\
\text { Score }\end{array}$ & $\begin{array}{c}\text { Raw } \\
\text { Score } \\
\text { (s) }\end{array}$ & $\begin{array}{c}\text { CHАMP } \\
\text { Score }\end{array}$ \\
\hline$\overline{\text { Mean } \pm \text { SD }}$ & $21.83 \pm 7.8$ & $25.04 \pm 14.60$ & $4.02 \pm 2.26$ & $15.39 \pm 5.54$ & $4.16 \pm 1.84$ & $25.46 \pm 17.86$ & $7 \pm 2.32$ & $32.09 \pm 12.81$ & $6.69 \pm 2.30$ \\
\hline Minimum & 1.00 & 0.00 & 0 & 3 & 0 & 123.72 & 1 & 87.27 & 0 \\
\hline 25th Percentile & 17.00 & 5.66 & 1 & 11 & 3 & 29.03 & 6 & 40.85 & 5 \\
\hline 50th Percentile & 23.00 & 31.26 & 5 & 15 & 4 & 18.94 & 8 & 26.77 & 8 \\
\hline 75th Percentile & 28.25 & 32.70 & 5 & 20 & 6 & 14.60 & 9 & 21.35 & 9 \\
\hline Maximum & 35.00 & 60.00 & 10 & 32 & 10 & 10.91 & 10 & 17.63 & 9 \\
\hline
\end{tabular}

ESST = Edgren Side Step Test, IAT = Illinois Agility Test, SD = standard deviation, SLS = Single Limb Stance. 
The SEM for the CHAMP was determined using the total CHAMP score test-retest reliability coefficient $(r=$ 0.97 ) and SD (7.8 points). The SEM for the CHAMP score was 1.35 points.

The MDC for the total CHAMP score was determined using the z-score (1.96) for 95 percent CI, total CHAMP score ICC for test-retest reliability $(r=0.97)$, and SD (7.8 points). The MDC for the CHAMP score was 3.74 points (Table 6). The MDC for each of the CHAMP items was calculated using the $z$-score (1.96) for 95 percent $\mathrm{CI}$ and ICC for the CHAMP item test-retest reliability.

Good correlations were found between the CHAMP score and each CHAMP item (from $r=0.78$ to $r=0.95, p<$ 0.001) (Table 7). As well, moderate to good correlations (from $r=0.56$ to $r=0.94, p<0.001$ ) were found between the CHAMP items (Table 7). The Cronbach $\alpha$ was 0.910 , which indicates high internal consistency among the CHAMP items in measuring high-level mobility. Table 8 details how each CHAMP item is correlated with the CHAMP score when omitting each item separately from

Table 5.

Interrater $(n=118)$ and test-retest reliability $(n=111)$ of Comprehensive High-Level Activity Mobility Predictor (CHAMP) items and total CHAMP score for U.S. servicemembers with traumatic lower-limb loss.

\begin{tabular}{|c|c|c|}
\hline CHAMP Test Item & $\begin{array}{c}\text { Interrater ICC, } \\
r(95 \% \mathrm{CI})\end{array}$ & $\begin{array}{c}\text { Test-Retest ICC, } \\
r(95 \% \text { CI })\end{array}$ \\
\hline \multicolumn{3}{|l|}{ Single Limb Stance } \\
\hline Right Limb & 1.0 (NA) & $0.97(0.95-0.97)$ \\
\hline Left Limb & 1.0 (NA) & $0.99(0.98-0.99)$ \\
\hline Edgren Side Step Test & $0.97(0.95-0.98)$ & $0.91(0.87-0.93)$ \\
\hline T-Test & 1.0 (NA) & $0.98(0.97-0.98)$ \\
\hline Illinois Agility Test & 1.0 (NA) & $0.97(0.95-0.97)$ \\
\hline Total CHAMP Score & 1.0 (NA) & $0.97(0.95-0.98)$ \\
\hline
\end{tabular}

Table 6.

Minimal detectable change (MDC) values for Comprehensive HighLevel Activity Mobility Predictor (CHAMP) items and total CHAMP score for U.S. servicemembers with traumatic lower-limb loss.

\begin{tabular}{lc}
\hline Outcome Measure (points) & MDC \\
\hline Total CHAMP Score & 3.74 \\
Single Limb Stance & 1.09 \\
Edgren Side Step Test & 1.53 \\
T-Test & 0.91 \\
Illinois Agility Test & 1.10 \\
\hline
\end{tabular}

the total score. Only SLS demonstrated a lower, yet moderate, correlation $(r=0.58)$ and higher Cronbach $\alpha$ when removed (0.96).

\section{DISCUSSION}

Military rehabilitation clinicians identified the need to develop an instrument for use in young, athletic SMs with traumatic LLL to measure changes in high-level mobility occurring throughout the rehabilitation process. The CHAMP was created from a combination of existing performance-based tests that assessed balance, postural stability, coordination, power, speed, and agility. The findings of this study support the CHAMP as a safe and reliable measure of high-level mobility suitable for use in SMs with various levels of LLL, including those with multiple LLL. On average, it took less than 15 min to administer the

Table 7.

Relationship between Comprehensive High-Level Activity Mobility Predictor (CHAMP) items and CHAMP scores for U.S. servicemembers with lower-limb loss $(n=118)$.

\begin{tabular}{|c|c|c|c|c|c|}
\hline Test Item & $\begin{array}{c}\text { Total } \\
\text { CHAMP } \\
\text { Score }\end{array}$ & $\begin{array}{c}\text { SLS } \\
\text { Score }\end{array}$ & $\begin{array}{l}\text { ESST } \\
\text { Score }\end{array}$ & $\begin{array}{l}\text { T-Test } \\
\text { Score }\end{array}$ & $\begin{array}{c}\text { IAT } \\
\text { Score }\end{array}$ \\
\hline $\begin{array}{l}\text { Total } \\
\text { CHAMP } \\
\text { Score }\end{array}$ & - & $\begin{array}{l}r=0.76 \\
p<0.001\end{array}$ & $\begin{array}{l}\mathrm{r}=0.90 \\
p<0.001\end{array}$ & $\begin{array}{l}r=0.96 \\
p<0.001\end{array}$ & $\begin{array}{l}r=0.94 \\
p<0.001\end{array}$ \\
\hline SLS Score & - & - & $\begin{array}{l}r=0.52 \\
p<0.001\end{array}$ & $\begin{array}{l}r=0.60 \\
p<0.001\end{array}$ & $\begin{array}{l}r=0.56 \\
p<0.001\end{array}$ \\
\hline ESST Score & - & - & - & $\begin{array}{l}r=0.87 \\
p<0.001\end{array}$ & $\begin{array}{l}r=0.85 \\
p<0.001\end{array}$ \\
\hline T-Test Score & - & - & - & - & $\begin{array}{l}r=0.94 \\
p<0.001\end{array}$ \\
\hline IAT Score & - & - & - & - & - \\
\hline
\end{tabular}

Table 8.

Item-to-total correlation between Comprehensive High-Level Activity Mobility Predictor items using Cronbach $\alpha(n=118)$.

\begin{tabular}{lcc}
\hline \multicolumn{1}{c}{ Deleted Variable } & $\begin{array}{c}\text { Corrected Item - Total } \\
\text { Correlation }(\boldsymbol{r})\end{array}$ & Cronbach $\boldsymbol{\alpha}$ \\
\hline Single Limb Stance & 0.58 & 0.96 \\
Edgren Side Step Test & 0.83 & 0.88 \\
T-Test & 0.92 & 0.84 \\
Illinois Agility Test & 0.89 & 0.84 \\
\hline \hline
\end{tabular}


CHAMP, no unexpected adverse events occurred during testing, and equipment required to administer the CHAMP is low in cost and can be easily purchased.

The SMs with LLL were representative of those SMs who have lost lower limbs while serving overseas or stateside during OIF/OEF. As of September 1, 2010, $1,073 \mathrm{SMs}$ had experienced major limb amputation in the recent conflicts [35]. We were able to capture 14 percent of the total population of SMs who experienced major LLL during these conflicts [36]. The OIF/OEF amputation statistics from 2010 reported that 61 percent of the SMs had unilateral LLL and 20 percent had bilateral LLL [36]. The study sample was similar to the national military amputation statistics, with 78 and 22 percent of participants presenting with either unilateral or bilateral LLL, respectively.

The study participants with LLL reflected the increasing trend of SMs returning to AD following major LLL. Fisher reported to Congress that 11 percent of SMs with traumatic LLL $(n=105)$ had either qualified for Continuation on $\mathrm{AD}$, Continuation on Active Reserve, or Fit for Duty [1]. A recent study by Stinner et al. found that among SMs with combat-related amputation between October 1, 2001, and June 1, 2006, 16.5 percent remained on AD [2]. For our study sample, 27 percent remained on $\mathrm{AD}$ following traumatic LLL. Because of the recruiting strategies of the research team and the willingness of SMs with LLL to participate in this study, we were able to capture a greater number of participants who returned to $\mathrm{AD}$ as compared with previous studies.

The SMs with and without LLL demonstrated differences in age, height, weight, and waist circumference. Because of the large sample size, some of these differences between the two groups achieved statistical significance, indicating that they were unlikely to have happened by chance. Additionally, all differences could be explained whereby many of the SMs without LLL were predeployment and early in their military careers and those who were SMs with LLL had been deployed, been through rehabilitation, or retired. Therefore, a 3 year difference in age, greater body weight, and higher waist circumference would be expected [37-38]. Yet, a valid comparison can be made between both groups with respect to CHAMP performance because SMs with LLL who want to return to AD would be expected to perform high-level mobility at a comparable level with their peers without amputation. The normative data collected from the participants without LLL was used to establish thresholds in CHAMP performance
( $\geq 33$ points), which could be used to determine when an SM with LLL is performing at a level equivalent to their counterparts without LLL.

Women have taken part in wartime activity on and off the battlefield in every conflict fought by the United States. Since 1991, women have compromised at least 10 percent of all AD personnel, serving in key combat support functions, driving trucks, flying planes and helicopters, running prisoner of war facilities, directing artillery, and serving in port and construction battalions [39]. With a greater involvement in battlefield activity, there is a risk for traumatic musculoskeletal injury and potential for LLL. Two recent studies have examined female SMs who have experienced traumatic LLL in recent OIF/OEF conflicts $[2,32]$ and have reported similar return to $\mathrm{AD}$ rate as their male counterparts (18.2\% vs $16.4 \%$ ) [2]. Female SMs with traumatic LLL are required to perform high-level mobility activities in order to return to AD. Because female SMs were not included in this study, future research is needed to establish normative CHAMP data for female SMs to determine threshold levels of performance.

All CHAMP items required a complex combination of muscular recruitment, movement strategies, prosthetic competency, and athletic abilities. Components of the prerequisite movement skills include balancing over the prosthesis; generating lower-limb power to produce fast, explosive movement; and producing efficient motion in order to start and stop movement and change directions when moving in singular and multiple planes. SMs who have not demonstrated the minimum threshold CHAMP score of 33 points may benefit from rehabilitation intervention designed to address specific limited movement patterns.

The interrater reliability for the total CHAMP score and CHAMP item scores were excellent. The CHAMP was administered using simple, straightforward, standardized written instructions to score each item by timing performance or counting ESST intervals. The SMs with LLL demonstrated no appreciable change in function between the testing sessions, and therefore, the test-retest reliability all of the CHAMP items were found to be excellent, supporting the CHAMP as a stable, repeatable measure of high-level mobility.

The MDC for the total CHAMP score was established using the distribution-based method [33]. A change in CHAMP score equal to or greater than 3.74 points represents the minimal amount of change that exceeds measurement error in high-level mobility for 
SMs with traumatic LLL [40]. The MDC provides clinicians with guidance for interpreting changes in total CHAMP score. Changes exceeding 3.74 points may be interpreted as not likely attributable to errors related to measurement issues. The study reported in this article was cross-sectional and could not be used to establish the CHAMP's responsiveness to change. Future research will be required to examine the CHAMP's responsiveness to changes occurring over time during rehabilitation.

The CHAMP was designed to quantify high-level mobility and reflect the physical performance factors required for such an activity by producing a total score from the results of the four tests. Although scores on the ESST, T-Test, and IAT were strongly correlated, each test represents a unique aspect of high-level mobility. For example, the IAT assesses transverse plane motions that are not included in any of the other tests. The ESST evaluates lateral motion but does not include the backward motion that is part of the T-Test. By combining all three tests with information from the SLS test, it is possible to generate a score that represents the multifaceted construct of high-level mobility. Failing to assess two or more aspects of high-level mobility would leave both clinicians and SMs with an incomplete picture of the SMs' capabilities, possibly leading to incorrect decisions concerning return to high-level work or recreational activities and increasing the risk for injury.

A high degree of internal consistency is necessary for a new assessment instrument, because it allows the clinicians and researchers to interpret a composite score as a reflection of the different items [41-42]. The CHAMP's Cronbach $\alpha$ was 0.910 , indicating that the CHAMP test items have high internal consistency in measuring the different aspects of high-level mobility. We felt that all CHAMP items assess the physical performance factors of high-level mobility under different condition and in different planes of motion, which are consistent with highlevel activity such as recreation, sport, and return to AD. The Cronbach $\alpha$ increased with the removal of SLS, confirming that it measures a different aspect of high-level mobility than the ESST, T-Test, and IAT. SLS, which has been established as a measure of balance and postural stability, actually lowers the Cronbach $\alpha$ when included in the CHAMP test.

\section{CONCLUSIONS}

A new instrument called the CHAMP was created to meet the need for a high-level mobility outcome measure in order to evaluate functional mobility with a prosthesis in young, athletic SMs with traumatic LLL. The CHAMP combined four previously described physical performance tests (SLS, ESST, T-Test, and IAT) of balance, postural stability, coordination, power, speed, and agility. Standardized written instructions were developed and the methodology for calculating a total score was established. CHAMP normative data was established for SMs with and without LLL. A simple scoring system was developed for the CHAMP that quantifies high-level mobility performance on a scale from 0 to 40 , with scores of $\geq 33$ points equivalent to $\mathrm{AD}$ SMs without LLL. In summary, the CHAMP is a measure of high-level mobility found to have excellent interrater and test-retest reliability that can be administered in $\leq 15 \mathrm{~min}$.

\section{ACKNOWLEDGMENTS}

\section{Author Contributions:}

Study concept and design: R. S. Gailey, I. A. Gaunaurd, M. A. Raya, K. E. Roach.

Acquisition of data: A. A. Linberg, S. M. Campbell, D. M. Jayne. Analysis and interpretation of data: R. S. Gailey, I. A. Gaunaurd, K. E. Roach.

Drafting of manuscript: R. S. Gailey, I. A. Gaunaurd, M. A. Raya. Critical revision of manuscript for important intellectual content: M. A. Raya, R. S. Gailey, I. A. Gaunaurd, K. E. Roach, C. Scoville. Statistical analysis: I. A. Gaunaurd, K. E. Roach.

Study Supervision: R. S. Gailey, I. A. Gaunaurd.

Financial Disclosure: The authors have declared that no competing interests exist.

Funding/Support: This material was based on work supported by the Military Amputee Research Program and the Telemedicine and Advanced Technology Research Center (Prime Award No. W81XWH-06-2-0073). The U.S. Army Medical Research Acquisition Activity (Fort Detrick, Maryland) is the awarding and administering acquisition office. It was administered by the Henry M. Jackson Foundation for the Advancement of Military Medicine and the South Florida Veterans Affairs Foundation for Research and Education. Additional Contributions: The authors would like to thank COL (Ret) Rebecca Hooper, PhD, PT; COL (Ret) Paul D. Stoneman, PhD, MPT, DPT, OCS, SCS; SGM (Ret) Brad Halling, CP; Carlos GomezOrozco; Justin Z. Laferrier, PhD, MSPT, OCS, SCS, ATP, CSCS; Peter D. Harsch, CP; CAPT (Ret) Kathy Goldberg, MSPT; Nico Marcolongo; Matt Berliner, DPT; Jen Berrios, DPT; Todd Bowen, SPT; Sarah Carballo, DPT; Marcos Davy, SPT; Kayla Felderhoff, DPT; Erica Gagne, DPT; Heather Ganyard, DPT; Erick Harada, DPT; Justin Knapp-Wood, DPT; Carolyn Lindsay, SPT; Emily Lo, DPT; Megan 
Mannikko, DPT; Patrick G. Manrique, DPT; Karrie McDonough, DPT; Daniel G. Muller, DPT; Tiffany Palmisano, DPT; Jeremiah Randall, DPT, ATC; Emily Roberts, DPT; Jarrod Schechla, DPT; Catherine Stewart, SPT; Adam Stivala, DPT; and Christen Tucker, DPT, for their help with data acquisition and Orlando Gomez-Marin, MSc, $\mathrm{PhD}$, for his help with statistical analysis. Thank you for your dedication and countless hours of work contributed to make this project a success. The authors also thank the staff at the Frederick Physical Fitness Center, Funk Physical Fitness Center, and Womack at Fort Bragg; Center for the Intrepid, BAMC; Military Advanced Training Center, WRAMC; Amputee Care, Prosthetics, and Rehabilitation Department, NMCSD; Research Department, Miami Department of Veterans Affairs (VA) Healthcare System; South Florida Veterans Affairs Foundation for Research and Education; and Challenged Athletes Foundation Operation Rebound for their generous support of this project. Dr. Scoville is now with the Department of Rehabilitation, Walter Reed National Military Medical Center (WRNMMC), Bethesda, Maryland; Ms. Linberg is now with the Department of Defense-VA Extremity Trauma and Amputation Center of Excellence, Department of Rehabilitation, WRNMMC, Bethesda, Maryland; and Mr. Campbell is now with the San Antonio Military Medical Center, Fort Sam Houston, Texas. The CHAMP is reprinted with permission from Advanced Rehabilitation Therapy Inc, Miami, Florida (C2009).

Institutional Review: Approved by the IRBs at Womack, WRAMC Department of Clinical Investigation, WRAMC Human Use Committee (HUC), BAMC Department of Clinical Investigation, BAMC HUC, Army Clinical Investigation Regulatory Office, and Miami VA Healthcare System Human Studies Subcommittee. A research investigator reviewed and explained to each participant eligibility criteria, methodology, confidentiality, and potential risks involved in study participation. The participants' questions were asked prior to signing the IRB-approved informed consent and protected health information form.

Participant Follow-Up: The authors plan to inform participants of the publication of this study.

Disclaimer: The content of the information does not necessarily reflect the position or the policy of the Department of the Army, Department of the Navy, Department of Defense, or U.S. Government, and no official endorsement should be inferred.

\section{REFERENCES}

1. Fischer H. United States military casualty statistics: Operation Iraqi Freedom and Operation Enduring Freedom. Washington (DC): Congressional Research Service; 2009.

2. Stinner DJ, Burns TC, Kirk KL, Ficke JR. Return to duty rate of amputee soldiers in the current conflicts in Afghanistan and Iraq. J Trauma. 2010;68(6):1476-79.

[PMID:20068483]

http://dx.doi.org/10.1097/TA.0b013e3181bb9a6c

3. Pasquina PF. DOD paradigm shift in care of servicemembers with major limb loss. J Rehabil Res Dev. 2010;47(4): xi-xiv. [PMID:20803395] http://dx.doi.org/10.1682/JRRD.2009.04.0059
4. Gawande A. Casualties of war-military care for the wounded from Iraq and Afghanistan. N Engl J Med. 2004; 351(24):2471-75. [PMID:15590948]

http://dx.doi.org/10.1056/NEJMp048317

5. Pasquina PF, Fitzpatrick KF. The Walter Reed experience: Current issues in the care of the traumatic amputee. J Prosthet Orthot. 2006;18(6):119-22.

6. Semenick D. Testing protocols and procedures. In: Baechle TR, editor. Essentials of strength training and conditioning. 1st ed. Champaign (IL): Human Kinetics; 1994. p. 258-73.

7. Harman E, Pandorf C. Principles of test selection and administration. In: Baechle TR, Earle RW, editors. Essentials of strength training and conditioning. 2nd ed. Champaign (IL): Human Kinetics; 2000. p. 275-311.

8. Sharp MA, Knapik JJ, Walker LA, Burrell L, Frykman PN, Darakjy SS, Lester ME, Marin RE. Physical fitness and body composition after a 9-month deployment to Afghanistan. Med Sci Sports Exerc. 2008;40(9):1687-92. [PMID:18685520] http://dx.doi.org/10.1249/MSS.0b013e318176b978

9. Pauole K, Madole K, Garhammer J, Lacourse M, Rozenek R. Reliability and validity of the T-test as a measure of agility, leg power, and leg speed in college-aged men and women. J Strength Cond Res. 2000;14(4):443-50.

10. Chaouachi A, Brughelli M, Chamari K, Levin GT, Ben Abdelkrim N, Laurencelle L, Castagna C. Lower limb maximal dynamic strength and agility determinants in elite basketball players. J Strength Cond Res. 2009;23(5):1570-77. [PMID:19620905] http://dx.doi.org/10.1519/JSC.0b013e3181a4e7f0

11. Vescovi JD, McGuigan MR. Relationships between sprinting, agility, and jump ability in female athletes. J Sports Sci. 2008;26(1):97-107. [PMID:17852692] http://dx.doi.org/10.1080/02640410701348644

12. Vescovi JD, Brown TD, Murray TM. Descriptive characteristics of NCAA Division I women lacrosse players. J Sci Med Sport. 2007;10(5):334-40. [PMID:16962826] http://dx.doi.org/10.1016/j.jsams.2006.07.010

13. Gabbett TJ. Physiological characteristics of junior and senior rugby league players. Br J Sports Med. 2002;36(5): 334-39. [PMID:12351330] http://dx.doi.org/10.1136/bjsm.36.5.334

14. Caldwell BP, Peters DM. Seasonal variation in physiological fitness of a semiprofessional soccer team. J Strength Cond Res. 2009;23(5):1370-77. [PMID:19620929] http://dx.doi.org/10.1519/JSC.0b013e3181a4e82f

15. Voight M, Tippett S. Plyometric exercise in rehabilitation. In: Prentice WE, editor. Rehabilitation techniques in sports medicine. 2nd ed. St. Louis (MO): Mosby; 1994. p. 88-97.

16. Bolgla LA, Keskula DR. Reliability of lower extremity functional performance tests. J Orthop Sports Phys Ther. 1997;26(3):138-42. [PMID:9276854] 
17. United States Army Center for Health Promotion and Preventive Medicine. IET standardized physical training guide [Internet]. Aberdeen Proving Ground (MD): USACHPPM; [2005 Jan 4]. Available from: http://www.ihpra.org/aug\%20web\%202010/IED PT.pdf

18. Gailey RS, Roach KE, Applegate EB, Cho B, Cunniffe B, Licht S, Maguire M, Nash MS. The Amputee Mobility Predictor: An instrument to assess determinants of the lowerlimb amputee's ability to ambulate. Arch Phys Med Rehabil. 2002;83(5):613-27. [PMID:11994800]

19. Berg K, Wood-Dauphinee S, Williams JI. The Balance Scale: Reliability assessment with elderly residents and patients with an acute stroke. Scand J Rehabil Med. 1995; 27(1):27-36. [PMID:7792547]

20. Tinetti ME. Performance-oriented assessment of mobility problems in elderly patients. J Am Geriatr Soc. 1986;34(2): 119-26. [PMID:3944402]

21. Beekhuizen KS, Davis MD, Kolber MJ, Cheng MS. Testretest reliability and minimal detectable change of the hexagon agility test. J Strength Cond Res. 2009;23(7):2167-71. [PMID:19855348] http://dx.doi.org/10.1519/JSC.0b013e3181b439f0

22. Petschnig R, Baron R, Albrecht $M$. The relationship between isokinetic quadriceps strength test and hop tests for distance and one-legged vertical jump test following anterior cruciate ligament reconstruction. J Orthop Sports Phys Ther. 1998;28(1):23-31. [PMID:9653687]

23. Hamilton RT, Shultz SJ, Schmitz RJ, Perrin DH. Triple-hop distance as a valid predictor of lower limb strength and power. J Athl Train. 2008;43(2):144-51. [PMID:18345338]

24. Newton RU, Gerber A, Nimphius S, Shim JK, Doan BK, Robertson M, Pearson DR, Craig BW, Häkkinen K, Kraemer WJ. Determination of functional strength imbalance of the lower extremities. J Strength Cond Res. 2006;20(4): 971-77. [PMID:17194256]

25. Vrieling AH, van Keeken HG, Schoppen T, Otten E, Halbertsma JP, Hof AL, Postema K. Gait initiation in lower limb amputees. Gait Posture. 2008;27(3):423-30. [PMID:17624782] http://dx.doi.org/10.1016/j.gaitpost.2007.05.013

26. Lin SJ, Bose NH. Six-minute walk test in persons with transtibial amputation. Arch Phys Med Rehabil. 2008; 89(12):2354-59. [PMID:18976979]

http://dx.doi.org/10.1016/j.apmr.2008.05.021

27. Schoppen T, Boonstra A, Groothoff JW, de Vries J, Göeken LN, Eisma WH. The timed "up and go" test: Reliability and validity in persons with unilateral lower limb amputation. Arch Phys Med Rehabil. 1999;80(7):825-28.

[PMID:10414769]

http://dx.doi.org/10.1016/S0003-9993(99)90234-4

28. Jonsson E, Seiger A, Hirschfeld H. One-leg stance in healthy young and elderly adults: A measure of postural steadiness? Clin Biomech (Bristol, Avon). 2004;19(7): 688-94. [PMID:15288454]

http://dx.doi.org/10.1016/j.clinbiomech.2004.04.002

29. Keogh JW, Weber CL, Dalton CT. Evaluation of anthropometric, physiological, and skill-related tests for talent identification in female field hockey. Can J Appl Physiol. 2003; 28(3):397-409. [PMID:12955867]

http://dx.doi.org/10.1139/h03-029

30. Wilkinson M, Leedale-Brown D, Winter EM. Validity of a squash-specific test of change-of-direction speed. Int $\mathrm{J}$ Sports Physiol Perform. 2009;4(2):176-85.

[PMID:19567921]

31. Raven PB, Gettman LR, Pollock ML, Cooper KH. A physiological evaluation of professional soccer players. $\mathrm{Br} \mathrm{J}$ Sports Med. 1976;10(4):209-16. [PMID:1009297] http://dx.doi.org/10.1136/bjsm.10.4.209

32. Reiber GE, McFarland LV, Hubbard S, Maynard C, Blough DK, Gambel JM, Smith DG. Servicemembers and veterans with major traumatic limb loss from Vietnam war and OIF/ OEF conflicts: Survey methods, participants, and summary findings. J Rehabil Res Dev. 2010;47(4):275-97.

[PMID:20803399]

http://dx.doi.org/10.1682/JRRD.2010.01.0009

33. Haley SM, Fragala-Pinkham MA. Interpreting change scores of tests and measures used in physical therapy. Phys Ther. 2006;86(5):735-43. [PMID:16649896]

34. Beaton DE, Bombardier C, Katz JN, Wright JG. A taxonomy for responsiveness. J Clin Epidemiol. 2001;54(12): 1204-17. [PMID:11750189] http://dx.doi.org/10.1016/S0895-4356(01)00407-3

35. Scoville C. Military service members with traumatic lower limb loss during the Global War on Terror. 2010 Sep 1.

36. Scoville C. Amputations from OIF/OEF. Washington (DC): Amputee Patient Care Service, National Naval Medical Center, Walter Reed Army Medical Center; 2010.

37. Littman AJ, Jacobson IG, Boyko EJ, Powell TM, Smith TC; Millennium Cohort Study Team. Weight change following US military service. Int J Obes (Lond). 2012;37(2): 244-53. [PMID:22491091] http://dx.doi.org/10.1038/ijo.2012.46

38. Kurdibaylo SF. Obesity and metabolic disorders in adults with lower limb amputation. J Rehabil Res Dev. 1996; 33(4):387-94. [PMID:8895133]

39. Murdoch M, Bradley A, Mather SH, Klein RE, Turner CL, Yano EM. Women and war. What physicians should know. J Gen Intern Med. 2006;21(Suppl 3):S5-10. [PMID:16637946] http://dx.doi.org/10.1111/j.1525-1497.2006.00368.x

40. Portney LG, Watkins MP. Statistical measures of validity. In: Foundations of clinical research: Applications to practice. 3rd ed. Upper Saddle River (NJ): Pearson/Prentice Hall; 2009. p. 644-53. 
41. Hensen RK. Understanding internal consistency reliability estimates: A conceptual primer on coefficient alpha. Meas Eval Couns Dev. 2001;34(3):117-89.

42. Streiner DL, Norman GR. Validity. In: Health measurement scales: A practical guide to their development and use. 3rd ed. Oxford (England): Oxford University Press; 2003. p. 172-93.

Submitted for publication June 25, 2012. Accepted in revised form January 10, 2013.

This article and any supplementary material should be cited as follows:

Gailey RS, Gaunaurd IA, Raya MA, Roach KE, Linberg
AA, Campbell SM, Jayne DM, Scoville C. Development and reliability testing of the Comprehensive High-Level Activity Mobility Predictor (CHAMP) in male servicemembers with traumatic lower-limb loss. J Rehabil Res Dev. 2013;50(7):905-18.

http://dx.doi.org/10.1682/JRRD.2012.05.0099

ResearcherID/ORCID: Robert S. Gailey, PhD, PT: I-34582013; Ignacio A. Gaunaurd, PhD, MSPT: I-3490-2013

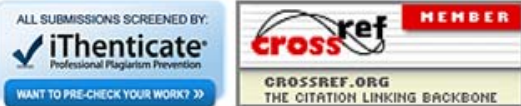

